\title{
Ethanol extract of asiasari radix preferentially induces apoptosis in G361 human melanoma cells by differential regulation of $\mathrm{p} 53$
}

\author{
Kwang-Ha Park ${ }^{1 \dagger}$, Jeong-Hae Choi ${ }^{1,2 \dagger}$, Yeon-Suk Song ${ }^{2}$, Gyoo-Cheon Kim ${ }^{1}$ and Jin-Woo Hong ${ }^{2^{*}}$ (D)
}

\begin{abstract}
Background: In Korea and China, asiasari radix (AR) is widely used as a traditional anti-inflammatory and analgesic agent. After its skin-regenerating and hair loss-preventing activities were identified, several types of AR extracts were used for aesthetic purposes. Nevertheless, the effect of ARE on various types of skin cancers was not fully studied yet.

Methods: In this study, we tested the effect of an ethanolic AR extract (ARE) on G361 human melanoma and HaCaT human keratinocyte cell lines. After ARE exposure, cell growth and the expression patterns of proteins and genes were monitored.

Results: The ARE-mediated cell growth inhibition was greater in G361 cells than in HaCaT cells due to differences in its cell growth regulation effects. Interestingly, ARE treatment induced caspase-3-mediated apoptosis in G361 cells, but not in HaCaT cells. Furthermore, ARE reduced the expression of p53 and p21 proteins in G361 cells, whereas it induced their expression in HaCaT cells. ARE induced cell death in G361 cells through the reactive oxygen species (ROS)-dependent regulation of p53 and p21 in G361 cells. Microarray analysis showed that ARE regulates Mouse double minute 2 homolog (MDM2) and CASP8 and FADD-like apoptosis regulator (CFLAR) gene expression in G361 and HaCaT cells differently.
\end{abstract}

Conclusion: The treatment of ARE preferentially induces apoptosis in melanoma cells by the ROS-dependent differential regulation of p53 level. Therefore, ARE can be used as a new medicinal option for melanoma.

Keywords: Asiasari radix, Melanoma, p53, MDM2, CFLAR, Reactive oxygen species, Microarray

\section{Background}

Asiasari radix (AR) has long been used in traditional Korean and Chinese medicine to treat cough, toothache, headache, neuralgia, gingivitis, asthma, and allergies due to its anti-bacterial and analgesic effects [1]. Recently, the pharmacological roles of AR extracts (AREs) have been reported. The anti-allergic [2,3] and anti-inflammatory $[4,5]$ activities of AREs have been confirmed in vitro and in vivo. AREs also exert an anti-carries activity

\footnotetext{
* Correspondence: jwhong@pusan.ac.kr

${ }^{\dagger}$ Kwang-Ha Park and Jeong-Hae Choi contributed equally to this work.

${ }^{2}$ Department of Internal Medicine, School of Korean Medicine, Yangsan

Campus of Pusan National University, Beomeo-ri, Mulgeum-eup, Yangsan-si,

Gyeongsangnam 50612, South Korea

Full list of author information is available at the end of the article
}

by not only reducing acid production, but also by inhibiting the growth and adhesion of Streptococcus mutans [6]. In addition, AREs also possess skin renewal and hair follicle-generating activities [7]. Furthermore, Jang et al. reported the possible skin-whitening role of ARE because it attenuates melanogenesis in rats [8]. Due to its potent skin regeneration and hair loss-preventing activities, AREs have been widely used in many cosmetics. Nevertheless, the effects of ARE on various types of skin cancers were studied poorly.

Melanoma is a type of skin cancer that accounts for about $4 \%$ of all cancers; however, it is the most dangerous since it accounts for about $80 \%$ of skin cancer-related deaths [9]. Although genetic risk factors contribute 
maximally to the development of melanoma, exposure to UV rays from the sun is directly or indirectly involved in the development of melanoma in $86 \%$ of the cases [10]. Fortunately, overall survival rate for patients with melanoma has gradually improved over the last 35 years due to improvement in detection systems along with surgical strategies. However, due to the lack of active agents for the treatment of melanoma, prognosis in patients diagnosed with malignant melanoma (stage IV) has remained grave [11]. One of the major goals of anti-cancer drug development is to selectively target cancer cells with high specificity [12]. Although numerous anti-melanoma drugs have been identified, the need for cancer cell-selective drugs is increasing gradually.

In this study, G361 human melanoma cells were treated with an ethanolic ARE for testing its role on cell proliferation and death. Furthermore, to compare the effects of ARE on keratinocytes with those on melanoma cells, we used $\mathrm{HaCaT}$ human keratinocytes to test whether ARE induces selective toxicity on melanoma cells. Furthermore, ARE-mediated changes in cell signaling pathways related with cell cycle regulation and apoptosis were determined using western blot analysis. In addition, the effects of ARE on gene expression patterns in the two cell lines were analyzed using cDNA microarray and RT-PCR analyses. Taken together, the results of this study indicate that ARE selectively induces apoptosis in melanoma cells, and presents an attractive approach for melanoma treatment.

\section{Methods}

\section{Reagents}

All chemicals were purchased from Sigma-Aldrich, Korea unless otherwise indicated.

\section{Cell culture}

$\mathrm{HaCaT}$ (which were used in our previous reports [13-15]) and G361 cells (purchased from ATCC ${ }^{\bullet}$, Manassas,USA) were maintained in Dulbecco's Modified Eagle's Medium (DMEM, Gibco, Grand Island, NY, USA) supplemented with $1 \%$ penicillin/streptomycin (Gibco) and $10 \%$ fetal bovine serum (FBS, Gibco). Cells were incubated at $37^{\circ} \mathrm{C}$ and $5 \% \mathrm{CO}_{2}$.

\section{ARE preparation}

The root of Asiasarum heterotropoides (AR) was purchased from Hwalim pharmaceutical company (Seoul, South Korea). Dried AR (200 g) was finely ground and immersed in 21 of $70 \%(\mathrm{v} / \mathrm{v})$ ethanol at $60^{\circ} \mathrm{C}$ for $16 \mathrm{~h}$. The extracts were filtered, and excess solvent was evaporated under reduced pressure using a rotary evaporator at $40^{\circ} \mathrm{C}$. The powdered extract $(21 \mathrm{~g})$ was homogenized using a mortar and pestle, and stored at $-70^{\circ} \mathrm{C}$ until further analysis. The recovery yield of the extracts was approximately $10 \%(\mathrm{w} / \mathrm{w})$. A working solution of ARE was prepared by dissolving the powder in dimethyl sulfoxide (DMSO) that was further diluted to obtain suitable concentrations.

\section{Cell growth assay using sulforhodamine $B$ (SRB)}

G361 and $\mathrm{HaCaT}$ cells were seeded in 24-well plates $\left(1 \times 10^{5}\right.$ cells/well $)$ and incubated for $24 \mathrm{~h}$. For testing the dose-dependent effects of ARE, the cells were treated with $0,200,400,600,800$, and $1000 \mu \mathrm{g} / \mathrm{ml}$ of ARE, and incubated for $24 \mathrm{~h}$ further. For testing the long-term effects of ARE, the cells were incubated for 24, 48, and 72 $h$ in a growth medium containing $0,200,400$, and $600 \mu \mathrm{g} / \mathrm{ml}$ of ARE. After incubation, the medium was gently removed, and the cells were fixed with $500 \mu \mathrm{l}$ of $4 \%$ paraformaldehyde for $30 \mathrm{~min}$ at room temperature. After removing the paraformaldehyde, the cells were washed with tap water several times and stained with 0.4\% SRB solution following the standard protocol of the SRB assay. After removing the SRB solution, the plates were washed with $1 \%$ acetic acid to ensure the complete removal of the SRB dye, and the plates were dried completely. The cells were imaged using optical microscopy, and $10 \mathrm{mM}$ Tris buffer was added to each well to dissolve the SRB dye. SRB intensity in each sample was detected using UV spectroscopy at $515 \mathrm{~nm}$.

\section{SDS-PAGE and western blot analysis}

G361 and $\mathrm{HaCaT}$ cells were seeded in $60-\mathrm{mm}$ cell culture dishes $\left(1 \times 10^{6}\right.$ cells). For testing the dosedependent effects of ARE, the cells were treated with ARE at 200, 400,600, 800, and $1000 \mu \mathrm{g} / \mathrm{ml}$ and incubated for $24 \mathrm{~h}$. To evaluate the time-dependent effects of ARE, the cells were treated with $1 \mathrm{mg} / \mathrm{ml}$ of ARE at 2, 4, 6,8 , and $12 \mathrm{~h}$. For the experiments using kinase inhibitors and NAC (N-acetyl-L-cysteine), the cells were exposed to the inhibitor $1 \mathrm{~h}$ before treatment with $1 \mathrm{mg} / \mathrm{ml}$ of ARE. The total incubation time of the cells was maintained as $48 \mathrm{~h}$ after cell seeding. After a final incubation, the cells were washed with PBS and harvested in ice-cold lysis buffer containing $50 \mathrm{mM}$ Tris/ $\mathrm{HCl}$ (pH 7.5), 150 $\mathrm{mM} \mathrm{NaCl}, 1 \%(\mathrm{v} / \mathrm{v})$ Nonidet P40, 10\% (v/v) glycerol, 1 mM PMSF, $1 \mathrm{mM}$ dithiothreitol, $20 \mathrm{mM} \mathrm{NaF}, 1 \mathrm{mM}$ EDTA, and a protease inhibitor cocktail (Roche). Equal amounts of cell lysate $(30 \mu \mathrm{g})$ were resolved by SDS/ PAGE $(8-12 \%$ gel) and transferred to PVDF membranes. Upon the completion of transfer, the membranes were probed with antibodies against poly (ADP-ribose) polymerases (PARP), p53, p21, c-Jun N-terminal kinases (JNK), phospho-JNK, p38 $\alpha / \beta$, phospho-p38, cyclin A, cyclin D1 (Santa Cruz Biotechnology, CA, USA), and cleaved-caspase-3 (Cell Signaling Technology, MA, USA). The specific bands were detected with advanced ECL western blotting reagents (Merck Millipore, 
Darmstadt, Germany). An anti-GAPDH antibody was used as a loading control (Santa Cruz Biotechnology).

\section{CDNA microarray}

G361 cells and $\mathrm{HaCaT}$ cells were seeded in $60-\mathrm{mm}$ cell culture dishes for $48 \mathrm{~h}$. Further, the cells were treated with $1 \mathrm{mg} / \mathrm{ml}$ of ARE and incubated for $4 \mathrm{~h}$. Cellular RNA was isolated using the TRIzol ${ }^{\mathrm{Tx}}$ reagent (Thermo Fisher Scientific, DE, USA). The extracted RNA purity was determined at $260 / 280 \mathrm{~nm}$ using a NanoDrop 1000 spectrophotometer (Thermo Fisher Scientific) before using the RNA samples for cDNA microarray analysis (GenomicWorks, Daejeon, Korea).

\section{RT-PCR analysis}

G361 cells and $\mathrm{HaCaT}$ cells were seeded in $60-\mathrm{mm}$ cell culture dishes and incubated for $48 \mathrm{~h}$. Further, the cells were treated with $1 \mathrm{mg} / \mathrm{ml}$ of ARE for $4 \mathrm{~h}$, and total RNA was isolated using the TRIzol ${ }^{\mathrm{Tu}}$ reagent (Thermo Fisher Scientific). The specific methods for RT-PCR can be found in our previous report [13]. Specific primers against MDM2 (sense: CGGAACAAGAGACCCTGG, antisense: GAGTCCGATGATTCCTGC TG) and CFLAR (sense: TGCCCTTATCTAGCAGGGA, antisense: CAGG AGTGGGCGTTTTCT) were used. After PCR analysis, the samples were electrophoresed on $1.5 \%$ agarose gel containing ethidium bromide. The gels were imaged by ImageQuant Las (GE Healthcare Life Sciences, Freiburg, Germany) image analyzer.

\section{Data analysis}

Data are presented as the mean \pm standard error of the mean (SEM) of at least three independent experiments. The two-tailed Student's $t$-test was used to assess statistical significance for differences in means, and the significance was set at $p<0.05$.

\section{Results}

The treatment of ARE preferentially inhibits the growth of G361 human melanoma cells in a dose-dependent manner

The effects of ARE on the growth of G361 melanoma cells and $\mathrm{HaCaT}$ human normal keratinocytes were tested. At first, the cells were treated with ARE at concentration of $62.5,125,250,500$ and $1000 \mu \mathrm{g} / \mathrm{ml}$ for $24 \mathrm{~h}$ and then the cell density were monitored. The results showed that ARE treatment significantly decreased the growth of G361 cells in a dose-dependent manner (Fig. 1a). Interestingly, although $1 \mathrm{mg} / \mathrm{ml}$ of ARE also decreased the cell density of $\mathrm{HaCaT}$ cells, the decrease was lesser in $\mathrm{HaCaT}$ cells than in G361 cells. This phenomenon was confirmed further by monitoring the effect of ARE (at concentration of 200, 400, 600, 800 and $1000 \mu \mathrm{g} / \mathrm{ml}$ ) on the growth rates of the two cells at $24 \mathrm{~h}$ after the treatment (Fig. 1b). ARE at concentrations above $600 \mu \mathrm{g} / \mathrm{ml}$ showed higher growth inhibition in G361 cells than in $\mathrm{HaCaT}$ cells. Especially, 37\% of $\mathrm{HaCaT}$ cells were still remained at $24 \mathrm{~h}$ after the treatment with $1 \mathrm{mg} / \mathrm{ml}$ of ARE; however, only 3\% of G361 cells were survived at same condition.

Further, the cells were treated with ARE at 200, 400, and $600 \mu \mathrm{g} / \mathrm{ml}$, and the growth of G361 and $\mathrm{HaCaT}$ cells were monitored at 24,48 , and $72 \mathrm{~h}$ after treatment. Similar to our previous results, the effects of ARE did not show significant differences between the two cell lines at all concentrations at $24 \mathrm{~h}$ after treatment (Fig. 2a). However, at $48 \mathrm{~h}$ after treatment, the growth inhibition effects of ARE on G361 cells were much greater than those on $\mathrm{HaCaT}$ cells, and significant differences between the two cells were observed at concentrations of $400 \mu \mathrm{g} / \mathrm{ml}$ or greater (Fig. 2b). Interestingly, ARE treatment at 200 and $400 \mu \mathrm{g} / \mathrm{ml}$ for $72 \mathrm{~h}$ slightly increased the growth of $\mathrm{HaCaT}$ cells; however, it decreased the growth of G361 melanoma cells (Fig. 2c).

\section{The treatment of ARE induces apoptosis in G361 cells but not in $\mathrm{HaCaT}$ cells}

For a more detailed understanding of the differential effects of ARE on G361 and HaCaT cells, the expression of molecular markers of cell death and growth arrest were monitored (Fig. 3). The treatment of ARE greatly increased the expression of apoptotic cell death marker proteins, cleaved caspase- 3 and PARP, in G361 cells in a dose-dependent manner (Fig. 3a) but not in $\mathrm{HaCaT}$ cells (Fig. 3b). The effect of ARE on cell cycle-regulating cyclins were not significant in both cells. However, AREmediated changes in the expression of p21 and p53 proteins in G361 cells were significantly different from those in $\mathrm{HaCaT}$ cells. The treatment of ARE decreased the expression of p53 in G361 cells but not in $\mathrm{HaCaT}$ cells. Furthermore, the expression of p21 in G361 cells was significantly reduced by ARE treatment in a dosedependent manner; however, ARE significantly increased the expression of p21 in $\mathrm{HaCaT}$ cells.

\section{The treatment of ARE induces the rapid cleavage of caspase-3 and PARP in G361 cells by decreasing p21 and p53 expression}

To identify cellular stress-related signaling proteins responsible for ARE-mediated apoptosis, the effect of ARE on the activities of JNK, p38, and other apoptosis-related proteins in G361 and $\mathrm{HaCaT}$ cells were monitored at several time points after treatment. ARE at $1 \mathrm{mg} / \mathrm{ml}$ immediately induced the apoptosis in G361 cells by increasing the cleavage of caspase- 3 , and cleaved PARP was detected at $4 \mathrm{~h}$ after treatment (Fig. 4a). Furthermore, ARE-mediated decrease in p21 and p53 was detected at $2 \mathrm{~h}$ after treatment. However, ARE treatment 


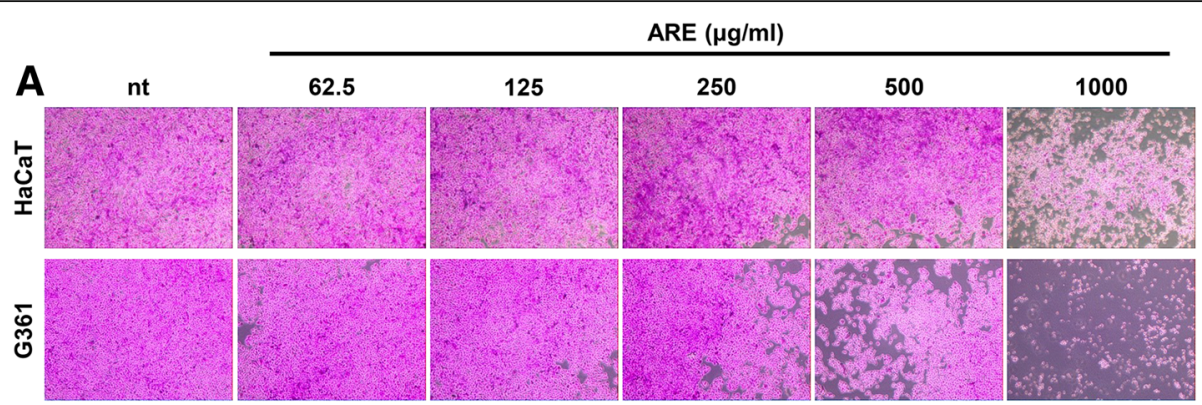

B

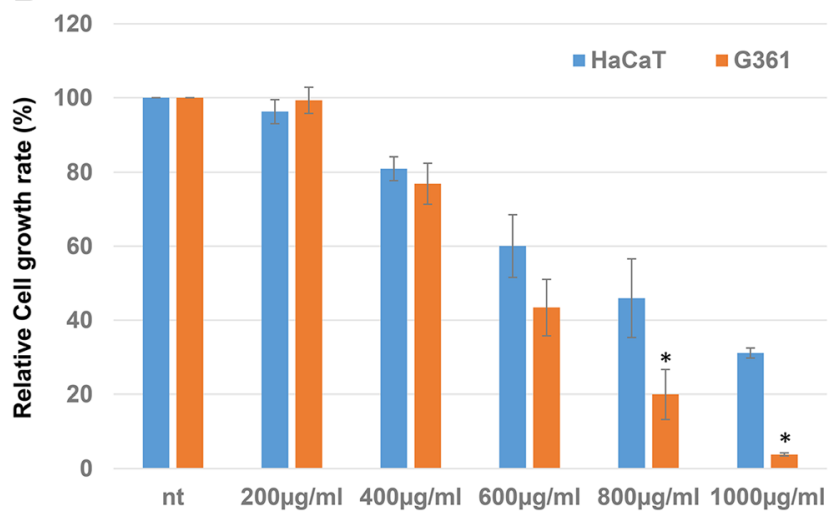

Fig. 1 Dose-dependent effects of ethanolic extract of asiasari radix (ARE) on the growth of G361 melanoma cells and HaCaT keratinocytes. a Microscopic images of G361 and HaCaT cells after $24 \mathrm{~h}$ of incubation with 0, 62.5, 125, 250, 500, and $1000 \mathrm{\mu g} / \mathrm{ml}$ of ARE. Total cellular protein was stained with SRB; data shown are representative of three independent experiments. b Dose-dependent effects of ARE (200, 400, 600, 800 and $1000 \mathrm{\mu g} / \mathrm{ml}$ ) on the growth rate of $\mathrm{G} 361$ and HaCaT cells were tested at $24 \mathrm{~h}$ after the treatment, using the SRB assay. Data represent the mean $\pm \operatorname{SEM}(n=4)$. The significant difference between HaCaT and G361 cells were marked as * $(p<0.05)$; nt, non-treated control

did not induce the apoptotic cleavage of caspase- 3 and PARP in $\mathrm{HaCaT}$ cells (Fig. 4b). In fact, it significantly increased the expression of p21 and p53 proteins in $\mathrm{HaCaT}$ cells. In both cells, ARE slightly increased the phosphorylation of JNK; however, p38 activation was observed only in $\mathrm{HaCaT}$ cells.

The ARE-mediated apoptosis in G361 cells is mediated by reactive oxygen species (ROS)-dependent decrease in p21 and p53

The roles of JNK and p38 proteins in ARE-mediated apoptosis in G361 cells were identified using specific kinase inhibitors. Pretreatment with SB203580, a specific inhibitor of p38, decreased the basal expression of p21 and p53 proteins, and failed to block ARE-mediated decrease in the levels of these proteins (Fig. 5a). Furthermore, the inhibition of p38 enhanced ARE-mediated apoptosis in G361 cells. The effects of JNK inhibition (using SP600125) were similar to those of p38 inhibition; however, its effect on the ARE-mediated cleavage of PARP was milder than that of p38 inhibition.

The treatment of ARE on various types of cancer cells induces intracellular ROS production. To determine whether ROS-mediated signaling stimulates ARE-mediated apoptosis in G361 cells, the effect of a pan-ROS inhibitor, NAC, on ARE-mediated changes in G361 cells was tested. NAC not only reduced the ARE-mediated cleavage of caspase-3 and PARP, but also blocked ARE-mediated decrease in p21 and p53 protein levels (Fig. 5b).

\section{The treatment of ARE differentially regulates ROS- and apoptosis-related gene expression in G361 and HaCaT cells}

To elucidate the mechanism of the ARE-mediated regulation of p21 and p53 expression and apoptosis in G361 and $\mathrm{HaCaT}$ cells, the cells were treated with $1 \mathrm{mg} / \mathrm{mL}$ of ARE, incubated for $4 \mathrm{~h}$, and the total cellular RNA extracts were used for cDNA microarray analysis. The treatment of ARE altered the expression of 4359 out of 58,285 probes (increase in the expression of 2650 probes and decrease in the expression of 1709 probes) by at least 2-fold in G361 cells. However, it induced a 2-fold change in the expression of only 2304 probes (increase in the expression of 1286 probes and decrease in the expression of 1018 probes) in $\mathrm{HaCaT}$ cells.

To narrow down candidate genes responsible for the ARE-mediated differential regulation of p21 and p53 that induce apoptosis in G361 and $\mathrm{HaCaT}$ cells, all 

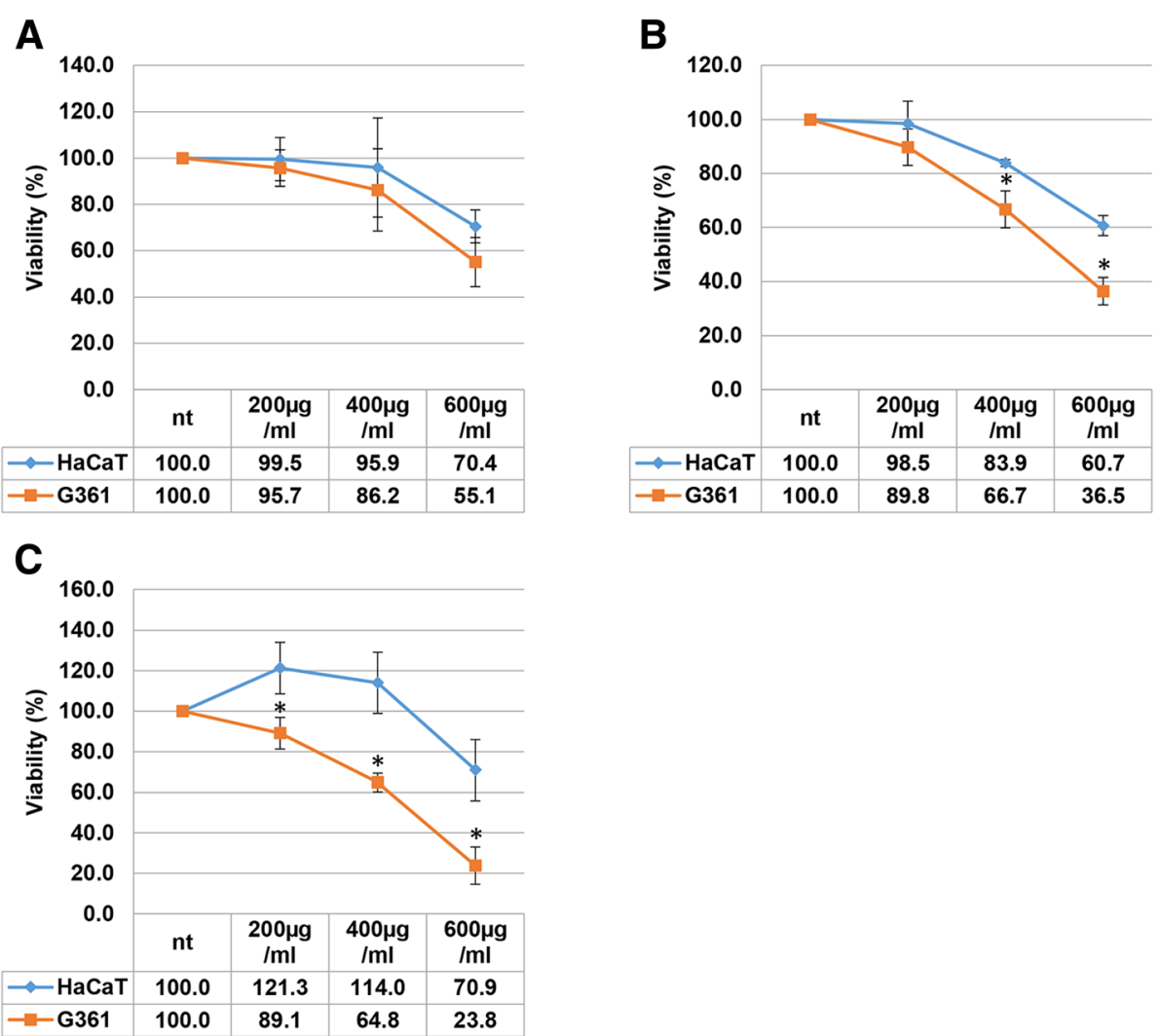

Fig. 2 Long-term effects of ARE on the growth of G361 and HaCaT cells. The growth of G361 and HaCaT cells were monitored at 24 (a), 48 (b), and $72 \mathrm{~h}$ (c) after ARE treatment at concentrations of 200, 400, and $600 \mu \mathrm{g} / \mathrm{ml}$ using the SRB growth assay. Data represent the mean \pm SEM $(n=4)$. The significant difference between HaCaT and G361 cells were marked as * $(p<0.05)$

probes related with apoptosis were searched under a standard list of genes (www.geneontology.org) using 'regulation of apoptotic process' as the keyword; AREmediated changes (1065 probes) in both cells are shown as a heat map (Fig. 6a). Because ARE-mediated cell death was effectively blocked by an ROS inhibitor, we searched for genes related to ROS production using 'cellular response to ROS' as the keyword; ARE-mediated changes (133 probes) are expressed as a heat map (Fig. 6b). Although some probes showed similar changes in both cells, others (109 probes in Fig. 6a and 18 probes in Fig. 6b) showed contrasting AREmediated changes in the two cell lines.

To further narrow down candidate genes responsible for the ARE-mediated preferential regulation of apoptosis in HaCaT and G361 cells, apoptosis- and ROS-related probes (Fig. 6a and b) that were oppositely affected by ARE treatment in the two cell lines were selected. These probes are described in Table 1. Among five key candidate genes, we focused on the differential effects of ARE on MDM2 and CFLAR (CASP8 and FADD-like apoptosis regulator) in $\mathrm{G} 361$ and $\mathrm{HaCaT}$ cells. The expression of MDM2 (a negative regulator of p53) was upregulated (2.89-fold) by ARE in G361 cells; however, it was downregulated (approximately 2-fold) in $\mathrm{HaCaT}$ cells. The other gene, CFLAR, also known as c-FLIP (FLICE-like inhibitory protein), is well known for its anti-apoptotic activity and is positively regulated by the p53 protein. The results of cDNA microarray analysis showed that ARE reduces (2.85-fold) CFLAR expression in G361 cells; however, it induces (2-fold) CFLAR expression in $\mathrm{HaCaT}$ cells. These results were further confirmed by performing RT-PCR analysis (Fig. 6c).

\section{Discussion}

Studies on the effects of AREs on the skin and hair have mainly focused on aesthetical benefits, including skin regeneration, skin whitening, and the prevention of hair loss. Therefore, AREs are commonly used in herbal skin-care products. However, their effects on various types of skin cancer cells have not been fully studied. Although they have been reported to exhibit anticancer effects on other types of cancers, including colon cancer [16], lung cancer [17, 18], and cervical cancer, specific mechanisms of action have not been uncovered.

Melanoma can be formed by malignant transformation of melanocytes, the cells in the skin responsible for pigment production [19]. Although the early stage 


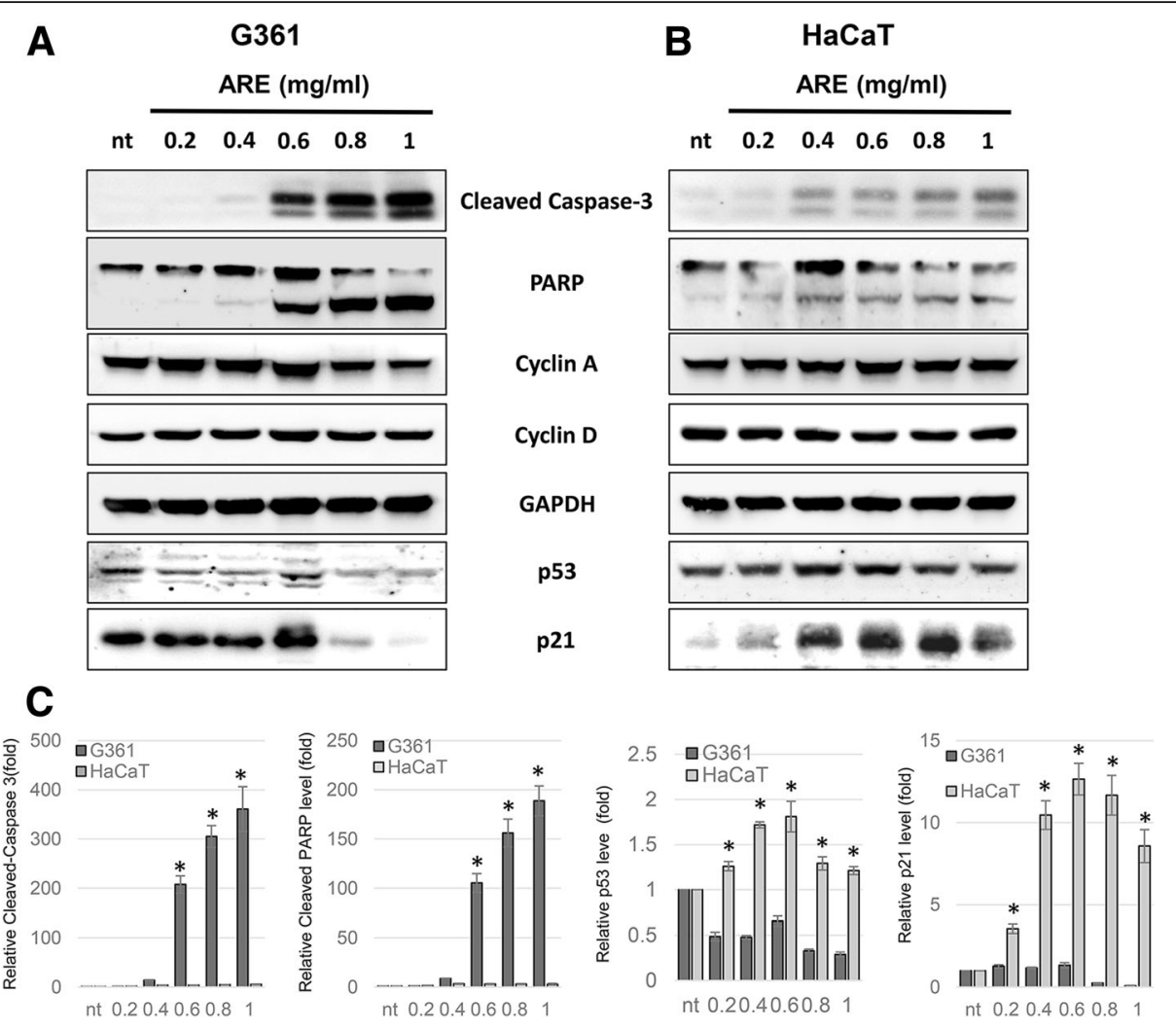

Fig. 3 Dose-dependent effects of ARE on the expression of apoptosis- and cell cycle-related proteins in G361 and HaCaT cells. The results of western blot analysis in $\mathrm{G} 361$ (a) and $\mathrm{HaCaT}$ (b) cells treated with $0.2,0.4,0.6,0.8$, and $1 \mathrm{mg} / \mathrm{ml}$ of ARE for $24 \mathrm{~h}$ are shown. GAPDH was used as a loading control. c The relative density of each protein of (A) and (B). Data represent the mean \pm SEM $(n=3)$. The significant difference between $\mathrm{HaCaT}$ and $\mathrm{G} 361$ cells were marked as * $(p<0.05)$

melanoma can be easily removed surgically, the late stage malignant melanoma cannot be treated easily because of their lack of responsiveness to currently available therapies [20]. In this study, the possible anticancer effects of an ethanolic ARE was tested against malignant melanoma. For this, the most frequently used G361 human melanoma cell line, which is also capable of melanogenesis was used [21]. To identify whether its actions were selective to cancer cells, its effects on $\mathrm{HaCaT}$ human keratinocytes were evaluated. Although $\mathrm{HaCaT}$ is an artificially constructed immortalized cell line, these cells can differentiate into epidermal cells of the skin [22]. Although treatment with ARE for $24 \mathrm{~h}$ reduced the proliferation of both cells, its effects on G361 were more severe than those on $\mathrm{HaCaT}$ cells at ARE concentrations of $0.8 \mathrm{mg} / \mathrm{ml}$ and greater (Fig. 1). Although the effects of ARE at concentrations of $0.2-0.6 \mathrm{mg} / \mathrm{ml}$ on $\mathrm{HaCaT}$ and G361 cells were similar at $24 \mathrm{~h}$ after treatment, ARE preferentially downregulated the growth of G361 cells at 48 and $72 \mathrm{~h}$ after treatment (Fig. 2). However, ARE treatment at concentrations of 0.2 and $0.4 \mathrm{mg} / \mathrm{ml}$ for $72 \mathrm{~h}$ slightly enhanced the growth of $\mathrm{HaCaT}$ cells. This finding corroborates previous reports on hair growth- promoting effects of AREs based on the increased proliferation of $\mathrm{HaCaT}$ and dermal papilla cells after low-dose ARE treatment [7]. These results indicate that the longterm exposure of the skin to AREs can selectively reduce the growth of melanoma cells. Although Lee et al. have reported that AREs preferentially inhibit the growth of A549 lung cancer cells [17], the mechanism of its selective anticancer effect remains unexplored.

Therefore, the effects of the ethanolic ARE on the expression of apoptosis- and cell cycle-related proteins in G361 and HaCaT cells were determined. ARE effectively increased the cleavage of caspase- 3 and PARP in G361 cells in a dose-dependent manner; however, no ARE-mediated change in these two proteins was detected in $\mathrm{HaCaT}$ cells (Fig. 3). Because the cleavage of these two proteins indicate apoptosis, it may be considered that the ARE-mediated growth inhibition of G361 cells is caused by apoptosis; however, ARE reduces the growth of $\mathrm{HaCaT}$ cells by other mechanisms. Although ARE treatment on the two cell lines did not modulate the expression of cell cycle-promoting proteins, the expression of p53 and p21, negative regulators of the cell cycle, were differently affected by ARE in G361 and 


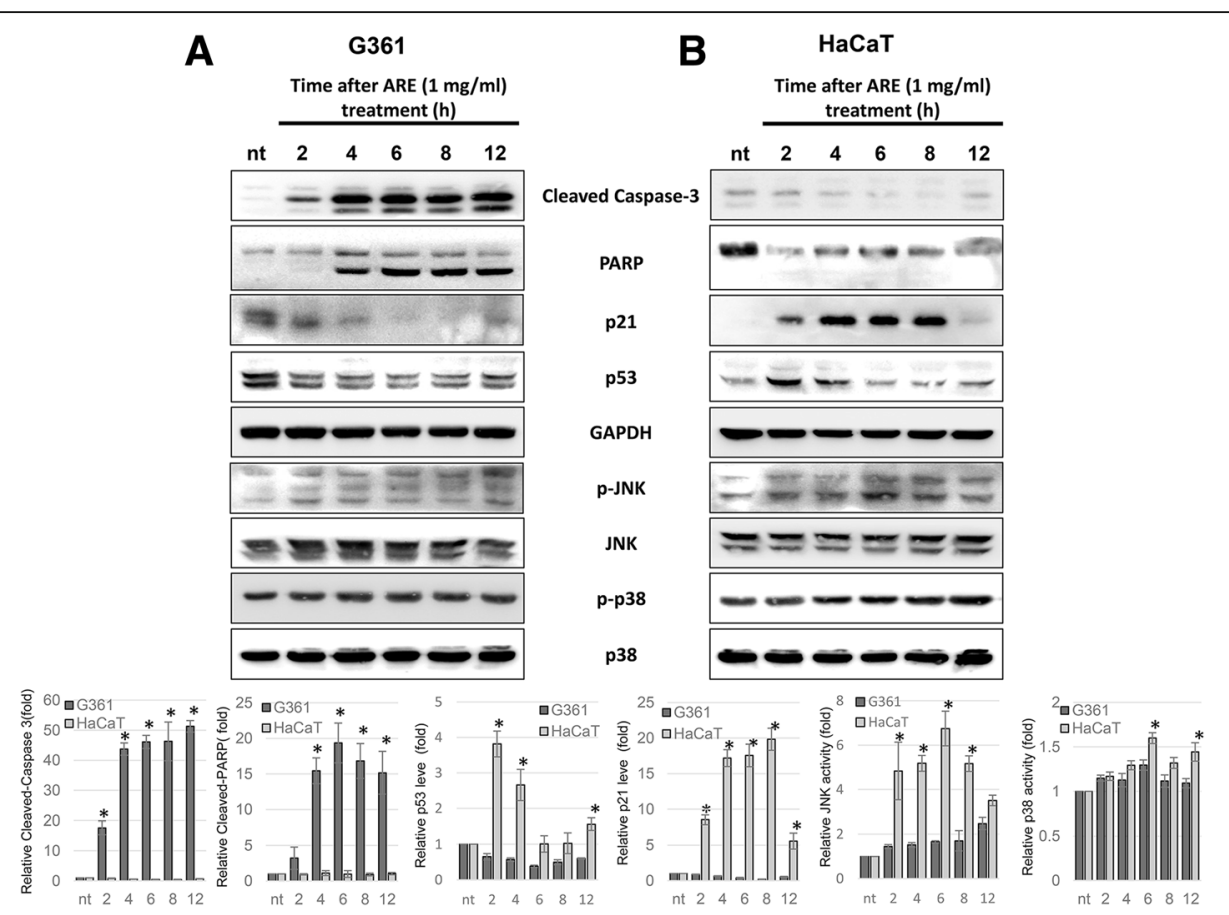

Fig. 4 Time-dependent effects of ARE on the expression of apoptosis- and stress-related proteins in G361 and HaCaT cells. The results of western blot analysis in G361 (a) and HaCaT (b) cells treated with $1 \mathrm{mg} / \mathrm{ml}$ of ARE for 2, 4, 6, 8, and $12 \mathrm{~h}$ are shown. The relative density of each proteins of (a) and (b) were represented as graphs (bottom panel). Data represent the mean \pm SEM $(n=3)$. The significant difference between HaCaT and G361 cells were marked as * $(p<0.05)$

HaCaT cells. In G361 cells, ARE treatment decreased the expression of $\mathrm{p} 53$ and $\mathrm{p} 21$ proteins, whereas in $\mathrm{HaCaT}$ cells, the expression of these two proteins was increased by ARE.

This differential effect of ARE on the cleavage of apoptotic proteins, and the expression of p21 and p53 in the two cell lines were confirmed in our time-dependent experiments (Fig. 4). In G361 cells, the cleavage of caspase-3 was induced at $2 \mathrm{~h}$ after ARE treatment, and PARP cleavage occurred after $4 \mathrm{~h}$. However, ARE treatment on HaCaT cells failed to induce the cleavage of caspase- 3 and PARP until $12 \mathrm{~h}$ after treatment. Caspase3 activation occurs last in the apoptotic caspase activation cascade, and cleaved-caspase- 3 actively promotes the cleavage of its substrate proteins, including PARP, leading to apoptosis [23]. PARP is normally overexpressed when cell DNA is damaged, and actively participates in DNA repair process. However, when DNA damage is too severe, PARP undergoes caspase-3-mediated cleavage to form an apoptosis-promoting protein [24]. Therefore, the effects of ARE on the cleavage of caspase- 3 and PARP in G361 cells indicate the ARE-mediated activation of the apoptotic caspase cascade. Along with apoptotic protein regulation, the ethanolic ARE differently regulated the expression of p53 and p21 proteins in the two cell lines. In G361 cells, ARE treatment immediately reduced the expression of p53 and p21 protein; however, their expression was increased in $\mathrm{HaCaT}$ cells. p53 is a major tumor suppressor protein, which is reported to be mutated in several cancers including melanoma. As a multi-functional protein, p53 actively regulates the expression of DNA repair and apoptosis-promoting genes [25]. p21 gene expression is positively regulated by $\mathrm{p} 53$. As a negative regulator of the cell cycle, p21 not only induces growth arrest, but also delays apoptosis under severe stress conditions [26]. Therefore, as shown in Fig. 4, ARE differentially regulates the expression of p53 and p21, and causes apoptosis in G361 cells and growth arrest in $\mathrm{HaCaT}$ cells.

What kind of stress-mediated signal pathway is participating in ARE-mediated p53 and p21 decrease and apoptotic cell death in G361 cells? According to the results shown in Fig. 5a, JNK and p38 kinases, well-known stress-signal mediators, are not responsible for ARE-mediated cell death in G361 cells. However, treatment with p38 and JNK inhibitors enhanced the ARE-mediated cleavage of caspase- 3 and PARP, and decreased the expression of $\mathrm{p} 53$ and $\mathrm{p} 21$ proteins. These effects might be because of the multi-functional properties of p38 and JNK. Although JNK and p38 proteins induce apoptosis under several stress conditions, they can be activated by growth factors to promote anti-apoptotic gene regulation [27, 28]. Especially, the role of p38 in apoptosis regulation is dependent on the type of cells, and Yee et al. reported that it causes G1 phase cell cycle arrest by 

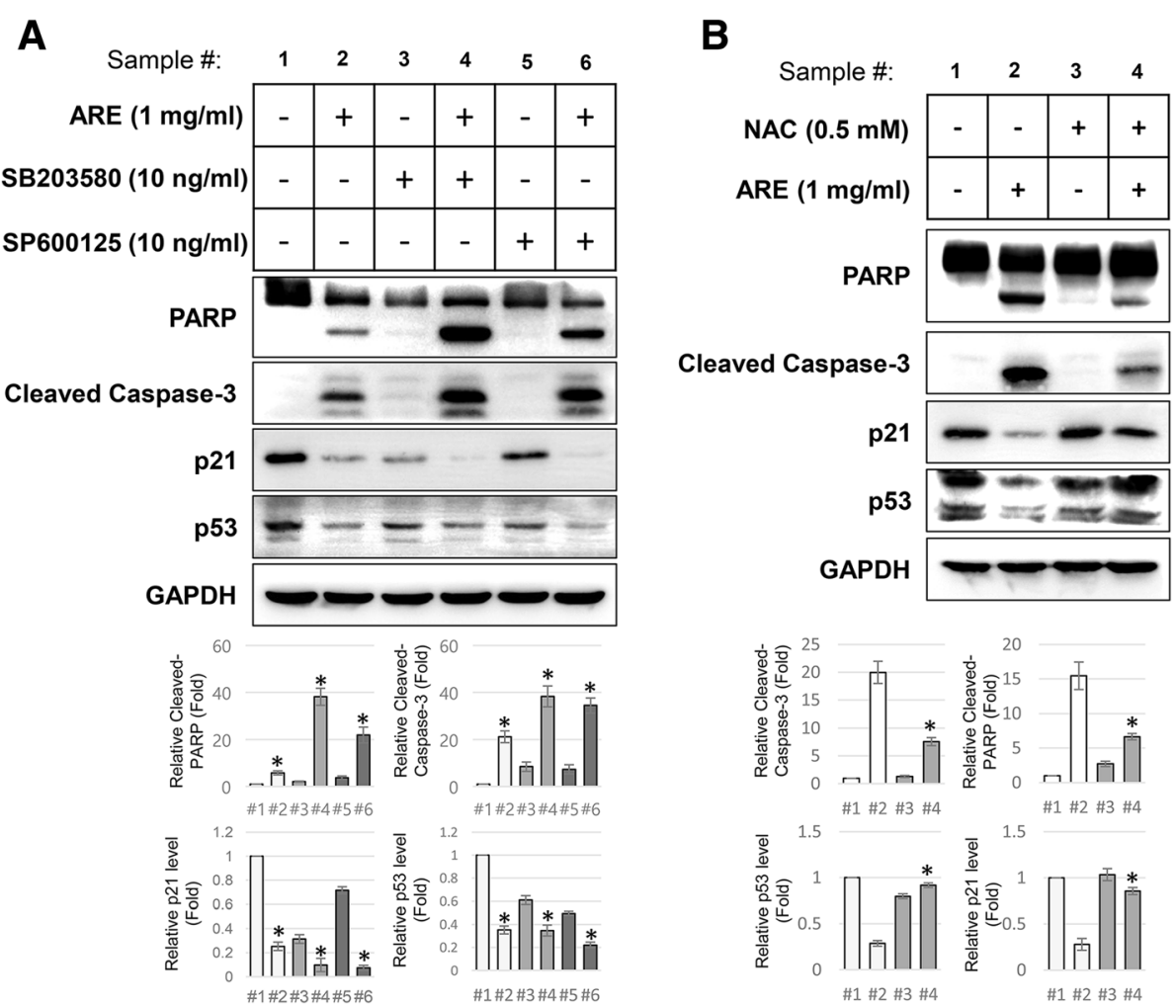

Fig. 5 ROS-dependent ARE-mediated apoptosis and the expression of p53 and p21 proteins in G361 cells. a The effects of specific inhibitors of JNK $(\mathrm{SP} 600125,10 \mathrm{ng} / \mathrm{ml})$ and p38 (SB203580, $10 \mathrm{ng} / \mathrm{ml})$ on ARE-mediated apoptosis and the expression of p53 and p21 proteins were tested using western blotting. The cells were pretreated with the inhibitors for $1 \mathrm{~h}$ before ARE $(1 \mathrm{mg} / \mathrm{ml}, 4 \mathrm{~h})$ treatment. The relative density of cleaved caspase-3 and -PARP, along with p21 and p53 were represented as graphs (bottom panel). Data represent the mean $\pm \operatorname{SEM}(n=3)$. The significant changes after ARE treatment were marked as * $(p<0.05)$ (b) The results of western blot analysis showing the effects of an ROS scavenger (NAC, $0.5 \mathrm{mM})$ on AREmediated effects in G361 cells are shown. The cells were pretreated with NAC for $1 \mathrm{~h}$ before ARE treatment. The relative density of each proteins were represented as graphs (bottom panel). Data represent the mean $\pm \operatorname{SEM}(n=3)$. The significant changes after ARE treatment were marked as * $(p<0.05)$
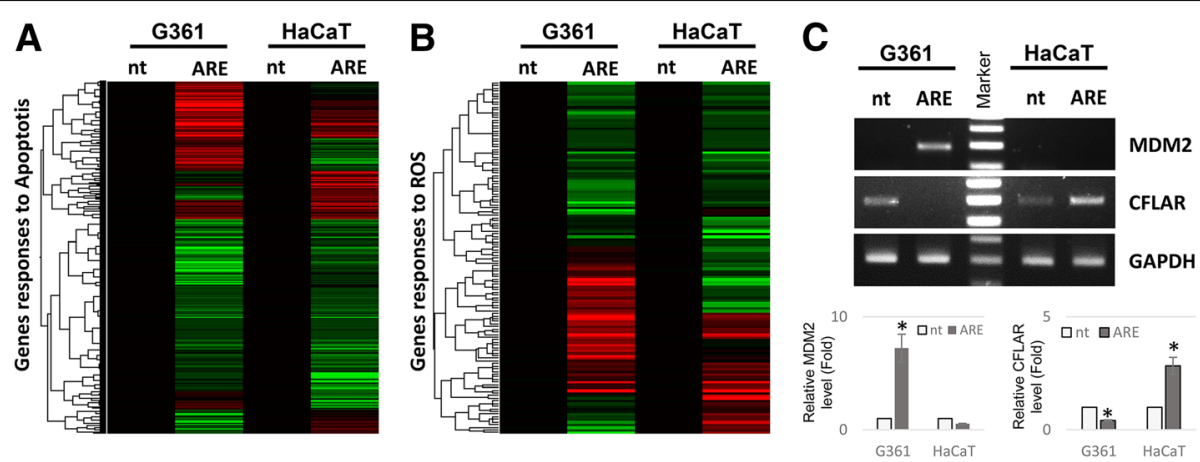

Fig. 6 CDNA microarray-based identification of MDM2 and CFLAR as genes responsible for ARE-mediated apoptosis in G361 cells. Genes showing more than 2-fold change after ARE treatment identified by CDNA microarray analysis using total RNA from G361 and HaCaT cells were classified into two groups; (a) apoptosis-related genes and (b) ROS-related genes. The change in gene expression levels in each group after ARE treatment is expressed as a heat map. The color intensity represents the extent of change; green indicates a decrease in gene expression, whereas red indicates an increase in gene expression. $\mathbf{c}$ The results of RT-PCR analysis of MDM2 and CFLAR genes are shown. GAPDH was used as a loading control. The relative expression of MDM2 and CFLAR mRNA were represented as graphs (bottom panel). Data represent the mean \pm SEM $(n=3)$. The significant changes after ARE treatment were marked as * $(p<0.05)$ Table 1. The list of ROS and apoptosis related genes those differently regulated by ARE in G361 and HaCaT cells. The significant changes after ARE treatment were marked as * $(p<0.05)$ 
Table 1 ROS and apoptosis related genes those differently regulated by ARE in G361 and HaCaT cells

\begin{tabular}{|c|c|c|c|c|c|c|}
\hline Gene Name & Gene Symbol & $\begin{array}{l}\text { UniGene } \\
\text { ID No. }\end{array}$ & GeneBank No. & Locus & $\begin{array}{l}\text { Mean Fold G361 } \\
(p \text { value) }\end{array}$ & $\begin{array}{l}\text { Mean Fold } \mathrm{HaCaT} \\
\text { ( } p \text { value) }\end{array}$ \\
\hline PRKC, apoptosis, WT1, regulator & PAWR & Hs.643130 & NM_002583 & $12 \mathrm{q} 21.2$ & $3.10^{*}(0.042)$ & $0.94(0.352)$ \\
\hline MDM2, proto-oncogene, E3 ubiquitin protein ligase & MDM2 & Hs.484551 & NM_002392 & $12 q 15$ & $2.89^{*}(0.005)$ & $0.50^{*}(0.038)$ \\
\hline Histone deactylase 2 & HDAC2 & Hs.3352 & NM_001527 & $6 q 21$ & $5.32^{*}(0.035)$ & $0.37^{*}(0.048)$ \\
\hline Receptor (TNFRSF)-interesting serine-threonine kinase 1 & RIPK1 & Hs.519842 & NM_003804 & $6 p 25.2$ & $0.32 *(0.018)$ & $1.07(0.418)$ \\
\hline CASP8 and FADD-like apoptosis regulator & CFLAR & Hs.390736 & NM_001202519 & $2 q 33.1$ & $0.35^{*}(0.001)$ & $2.00^{*}(0.029)$ \\
\hline
\end{tabular}

The significant changes after ARE treatment were marked as $*(p<0.05)$

activating p21 [29]. Accordingly, we observed that the inhibition of p38 further led to the ARE-mediated decrease in p21 activation, thereby causing enhanced AREmediated apoptosis in G361 cells.

In many kinds of cancer cells, excessive ROS can promote apoptotic cell death [30], and several natural plantderived compounds have been reported as potential anti-cancer drugs inducing ROS-dependent apoptosis [31]. In this study, ARE-mediated apoptosis in G361 cells was ROS-dependent. Treatment with NAC, an ROS scavenger, significantly reduced ARE-mediated caspase- 3 and PARP cleavage, and apoptosis, and decrease in p53 and p21 protein expression was prevented. These data indicate that an increase in cellular ROS decreases p53 and p21 protein expression to cause ARE-mediated apoptosis in G361 cells.

Finally, candidate genes responsible for the ARE-mediated differential regulation of apoptosis, and p53 and p21 expression in G361 and HaCaT cells were identified by performing a cDNA microarray analysis. Because ARE-mediated apoptosis occurred only in G361 cells, we measured changes in the expression of apoptosis-related genes (Fig. 6a). Because ARE induced apoptosis in G361 cells in an ROS-dependent manner, changes in the expression of ROS-related genes were also studied (Fig. 6b). Some genes showed similar expression patterns after ARE treatment in both the cell types; however, other genes were modulated differently by ARE. Despite being exposed to the same stress stimulus, ARE differentially regulated p53 and p21 expression, and apoptosis in G361 and HaCaT cells. As shown in Table 1, five genes were identified to be related to apoptosis and ROS that were differentially regulated by ARE in G361 and $\mathrm{HaCaT}$ cells. Among them, the expression of MDM2 and CFLAR genes is directly related with p53 protein level. As one of major negative regulators of p53, MDM2 protein promotes the ubiquitin-mediated degradation of p53 protein $[32,33]$. On the other hand, CFLAR is one of the target genes of p53 protein, and it binds to the death receptor signaling complex and inhibits apoptosis by blocking the activation of caspases [34, 35]. As shown in Fig. $6 \mathrm{c}$ and Table 1, ARE induces MDM2 gene expression in G361 cells, whereas it decreases its expression in
$\mathrm{HaCaT}$ cells. The expression pattern of CFLAR gene after ARE treatment was similar to that of p53; its expression decreased in G361 cells, whereas it increased in $\mathrm{HaCaT}$ cells. Therefore, these results indicate that AREmediated increase in ROS induces the expression of MDM2 in G361 cells, which can be directly linked to the decrease in p53 protein level and its target gene CFLAR. Because CFLAR is a caspase inhibitor, caspasemediated apoptosis in G361 cells upon ARE treatment is plausible. However, ARE reduced MDM2 gene expression and stimulated p53 protein and CFLAR gene expression in $\mathrm{HaCaT}$ cells, leading to the blockage of AREmediated caspase activation in these cells. In the future, we propose to elucidate the mechanism of the differential regulation of $M D M 2$ gene expression by ARE in the two types of cells.

\section{Conclusion}

In this study, the anticancer activity of ARE, which is frequently exposed to the skin as a component of aesthetic products was tested using a melanoma cell line The results of this study elucidate the noble anti-melanoma activity of ARE, which preferentially induces apoptosis in G361 melanoma cells rather than in immortalized keratinocytes. In addition, specific mechanisms for its anticancer activity have been suggested. ARE increases cellular ROS and differentially regulates the expression of $M D M 2$ gene in melanoma cells, thereby decreasing the expression of anti-apoptotic genes, such as $p 21$ and CFLAR, by negatively regulating p53 protein expression. Taken together, this study presents the possible roles of ARE as an anti-melanoma agent apart from its effects on skin regeneration and hair loss prevention.

\section{Abbreviations}

AR: Asiasari radix; ARE: Ethanol extract of AR; CFLAR: CASP8 and FADD-like apoptosis regulator; MDM2: Mouse double minute 2 homolog; NAC: Nacetyl-L-cysteine; PARP: Poly (ADP-ribose) polymerases; ROS: Reactive oxygen species; SRB: Sulforhodamine B

Acknowledgements

Not applicable. 


\section{Authors' contributions}

JHC, GCK and JWH designed the study and the study was supervised by JWH. Most of the experiments and the data analyzation were performed by KHP and $J H C$, and YSS assisted it. CJH and KHP wrote most of the manuscript, GCK and JWH advised it. All authors read and approved the final manuscript.

\section{Funding}

This research was supported by Basic Science Research Program through the National Research Foundation of Korea(NRF) funded by the Ministry of Education(NRF-2017R1D1A1B03031678). This work was also supported by clinical research grant from Pusan National University Hospital in 2019.

\section{Availability of data and materials}

All data generated or analyzed during this study are included in this published article.

\section{Ethics approval and consent to participate}

Not applicable.

\section{Consent for publication}

Not applicable.

\section{Competing interests}

The authors declare that they have no competing interests.

\section{Author details}

'Department of Anatomy and Cell Biology, School of Dentistry, Yangsan Campus of Pusan National University, Beomeo-ri, Mulgeum-eup, Yangsan-si, Gyeongsangnam 50612, South Korea. ${ }^{2}$ Department of Internal Medicine, School of Korean Medicine, Yangsan Campus of Pusan National University, Beomeo-ri, Mulgeum-eup, Yangsan-si, Gyeongsangnam 50612, South Korea.

Received: 13 February 2018 Accepted: 23 July 2019

Published online: 28 August 2019

\section{References}

1. Ramalingam M, Kim SJ. Phytochemical, toxicological and pharmacological studies of Asiasari Radix et Rhizoma: a review. Trop J Pharm Res. 2015;14(3): 545-54.

2. Hashimoto K, Yanagisawa T, Okui Y, Ikeya Y, Maruno M, Fujita T. Studies on anti-allergic components in the roots of Asiasarum sieboldi. Planta Med. 1994;60(2):124-7.

3. Kim HM, Moon YS. Asiasari radix inhibits immunoglobulin E production on experimental models in vitro and in vivo. Immunopharmacol Immunotoxicol. 1999;21(3):469-81.

4. Han AR, Kim HJ, Shin M, Hong M, Kim YS, Bae H. Constituents of Asarum sieboldii with inhibitory activity on lipopolysaccharide (LPS)-induced NO production in BV-2 microglial cells. Chem Biodivers. 2008;5(2):346-51.

5. Kim SJ, Gao Zhang C, Taek Lim J. Mechanism of anti-nociceptive effects of Asarum sieboldii Miq. Radix: potential role of bradykinin, histamine and opioid receptor-mediated pathways. J Ethnopharmacol. 2003;88(1):5-9.

6. Yu HH, Seo SJ, Hur JM, Lee HS, Lee YE, You YO. Asarum sieboldii extracts attenuate growth, acid production, adhesion, and water-insoluble glucan synthesis of Streptococcus mutans. J Med Food. 2006;9(4):505-9.

7. Rho SS, Park SJ, Hwang SL, Lee MH, Kim CD, Lee IH, Chang SY, Rang MJ. The hair growth promoting effect of Asiasari radix extract and its molecular regulation. J Dermatol Sci. 2005;38(2):89-97.

8. Jang JY, Lee JH, Shin HK, Choi YH, Lee JD, Choi BT. Partially purified Asiasari radix inhibits melanogenesis through extracellular signal-regulated kinase signaling in B16F10 cells. Int J Mol Med. 2010;25(2):287-92.

9. Miller AJ, Mihm MC Jr. Melanoma. N Engl J Med. 2006:355(1):51-65.

10. Parkin DM, Mesher D, Sasieni P. 13. Cancers attributable to solar (ultraviolet) radiation exposure in the UK in 2010. Br J Cancer. 2011;105(Suppl 2):S66-9.

11. Majer M, Jensen RL, Shrieve DC, Watson GA, Wang M, Leachman SA Boucher KM, Samlowski WE. Biochemotherapy of metastatic melanoma in patients with or without recently diagnosed brain metastases. Cancer. 2007; 110(6):1329-37.

12. Mak L, Liggi S, Tan L, Kusonmano K, Rollinger JM, Koutsoukas A, Glen RC, Kirchmair J. Anti-cancer drug development: computational strategies to identify and target proteins involved in cancer metabolism. Curr Pharm Des. 2013;19(4):532-77.
13. Choi JH, Lee HW, Lee JK, Hong JW, Kim GC. Low-temperature atmospheric plasma increases the expression of anti-aging genes of skin cells without causing cellular damages. Arch Dermatol Res. 2013;305(2):133-40.

14. Choi JH, Song YS, Song K, Lee HJ, Hong JW, Kim GC. Skin renewal activity of non-thermal plasma through the activation of beta-catenin in keratinocytes. Sci Rep. 2017;7(1):6146.

15. Lee HY, Lee HJ, Kim GC, Choi JH, Hong JW. Plasma cupping induces VEGF expression in skin cells through nitric oxide-mediated activation of hypoxia inducible factor 1. Sci Rep. 2019;9(1):3821.

16. Oh SM, Kim J, Lee J, Yi JM, Oh DS, Bang OS, Kim NS. Anticancer potential of an ethanol extract of Asiasari radix against HCT-116 human colon cancer cells in vitro. Oncol Lett. 2013;5(1):305-10.

17. Lee J, Lee YJ, Oh SM, Yi JM, Kim NS, Bang OS. Bioactive compounds from the roots of Asiasarum heterotropoides. Molecules. 2013;19(1):122-38.

18. Park JD, Baek NI, Lee YH, Kim SI. Isolation of a cytotoxic agent from asiasari radix. Arch Pharm Res. 1996;19(6):559-61.

19. Ohtani Y, Harada T, Funasaka Y, Nakao K, Takahara C, Abdel-Daim M, Sakai N, Saito N, Nishigori C, Aiba A. Metabotropic glutamate receptor subtype-1 is essential for in vivo growth of melanoma. Oncogene. 2008;27(57):7162-70.

20. Abdel-Daim M, Funasaka Y, Komoto M, Nakagawa Y, Yanagita E, Nishigori C. Pharmacogenomics of metabotropic glutamate receptor subtype 1 and in vivo malignant melanoma formation. J Dermatol. 2010;37(7):635-46.

21. Yamashita T, Tokino T, Tonoki H, Moriuchi T, Jin HY, Omori F, Jimbow K. Induction of apoptosis in melanoma cell lines by p53 and its related proteins. J Invest Dermatol. 2001;117(4):914-9.

22. Schoop VM, Mirancea N, Fusenig NE. Epidermal organization and differentiation of HaCaT keratinocytes in organotypic coculture with human dermal fibroblasts. J Invest Dermatol. 1999;112(3):343-53.

23. Elmore S. Apoptosis: a review of programmed cell death. Toxicol Pathol. 2007:35(4):495-516.

24. Morales J, Li L, Fattah FJ, Dong Y, Bey EA, Patel M, Gao J, Boothman DA Review of poly (ADP-ribose) polymerase (PARP) mechanisms of action and rationale for targeting in cancer and other diseases. Crit Rev Eukaryot Gene Expr. 2014;24(1):15-28

25. Bieging KT, Mello SS, Attardi LD. Unravelling mechanisms of p53-mediated tumour suppression. Nat Rev Cancer. 2014;14(5):359-70.

26. Abbas T, Dutta A, p21 in cancer: intricate networks and multiple activities. Nat Rev Cancer. 2009;9(6):400-14.

27. Dhanasekaran DN, Reddy EP. JNK signaling in apoptosis. Oncogene. 2008; 27(48):6245-51.

28. Zarubin T, Han J. Activation and signaling of the p38 MAP kinase pathway. Cell Res. 2005:15(1):11-8.

29. Yee AS, Paulson EK, McDevitt MA, Rieger-Christ K, Summerhayes I, Berasi SP, Kim J, Huang CY, Zhang X. The HBP1 transcriptional repressor and the p38 MAP kinase: unlikely partners in G1 regulation and tumor suppression. Gene. 2004:336(1):1-13.

30. Liou GY, Storz P. Reactive oxygen species in cancer. Free Radic Res. 2010; 44(5):479-96.

31. Lo YC, Lin YC, Huang YF, Hsieh CP, Wu CC, Chang IL, Chen CL, Cheng CH, Chen HY. Carnosol-induced ROS inhibits cell viability of human osteosarcoma by apoptosis and autophagy. Am J Chin Med. 2017:1-12

32. Brooks CL, Gu W. p53 ubiquitination: Mdm2 and beyond. Mol Cell. 2006; 21(3):307-15.

33. Nag S, Qin J, Srivenugopal KS, Wang M, Zhang R. The MDM2-p53 pathway revisited. J Biomed Res. 2013:27(4):254-71.

34. Micheau O. Cellular FLICE-inhibitory protein: an attractive therapeutic target? Expert Opin Ther Targets. 2003;7(4):559-73.

35. Bartke $T$, Siegmund D, Peters $N$, Reichwein M, Henkler F, Scheurich $P$, Wajant H. p53 upregulates CFLIP, inhibits transcription of NF-kappa Bregulated genes and induces caspase-8-independent cell death in DLD-1 cells. Oncogene. 2001:20(5):571-80.

\section{Publisher's Note}

Springer Nature remains neutral with regard to jurisdictional claims in published maps and institutional affiliations. 